\title{
EL MIEDO EN LA ARGUMENTACIÓN: UNA APROXIMACIÓN ÉTICA
}

\section{FEAR IN THE ARGUMENTATION: AN ETHICAL APPROACH \\ Henry Campos Vargas*}

A Marjorie, mi hermana

RESUMEN

Argumentar es un acto humano que, como tal, posee reglas. En este artículo se examina el temor en la argumentación con ayuda de la pragma-dialéctica.

PALABRAS CLAVE: TEMOR * ARGUMENTACIÓN * LÓGICA * ÉTICA* PRAGMA-DIALÉCTICA

ABSTRACT

Arguing is a human which has rules. In this article, we examine the fear in the argument using the pragma-dialectical.

KEYWORDS: FEAR * ARGUMENTATION * LOGIC * ETHICS * PRAGMA-DIALECTICAL

\section{1) ¿QUÉ ES ARGUMENTAR?}

Si bien, argumentar es una actividad mental, como lo son razonar y pensar, no se identifica con estas últimas pues, aunque "todo razonamiento exige la actividad de pensar, no todo pensamiento es un razonamiento" (Camacho, 1983: 114). Téngase presente, por ejemplo, que al recordar en nuestra memoria una imagen de nuestra infancia se está generando un tipo de pensamiento, empero, no un razonamiento. De manera semejante, al componer una canción se producen muchos tipos de pensamientos que no necesariamente, son razonamientos (como lo serían la descripción de los atributos físicos de la mujer amada, en el caso de una composición romántica).

La argumentación involucra el lenguaje, ya que ciertamente, es un fenómeno producto de su uso; no obstante, hay factores extralingüísticos que también intervienen en ella, tales como, costumbres, escalas de valores y ciertas prácticas sociales.

Argumentar se relaciona directamente con el carácter social del ser humano, es un tipo de interacción con los otros, lo cual implica, en palabras de Plantin, que "la argumentación en una lengua natural maneja conjuntamente la lógica y la retórica" (Plantin, 2008: 16). En este ámbito, la lógica opera como

* $\quad$ Escuela de Filología, Língüística y Literatura de la Universidad de Costa Rica (UCR). hcamposv@yahoo.es 
un verificador de la corrección de los razonamientos, constituye siempre la base de la argumentación; no en vano, una de las reglas indica expresamente que "todas las formas de argumentación deben ser válidas" (van Eemeren y Grootendorst, 2002: 187).

Sin embargo, junto al componente lógico se encuentra el retórico, el cual incide sobre nuestra capacidad de convencimiento. Este factor considera aspectos como el emisor, el canal y el receptor (para emplear conceptos de la semiótica), en el que ninguno de ellos es neutral. Esto se comprueba en la experiencia de no pocas personas (como los niños y las mujeres), quienes a menudo, no son escuchados por su sola condición (en este caso, el ser precisamente niños o mujeres). Tal y como puede apreciarse, este es un factor extraño a la lógica, pues apunta a la credibilidad del sujeto (el ethos, en palabras de Aristóteles), que en no pocas ocasiones ciega nuestra razón y capacidad de escuchar.

Argumentar es una práctica social exquisita que, como tal, puede estar afectada por vicios. Es importante, por ello, social e individualmente, argumentar bien, de manera correcta, elegante y precisa.

De acuerdo con van Eemeren, "la argumentación utiliza el lenguaje para justificar o refutar un punto de vista con el propósito de asegurar un acuerdo en las ideas" (2003: 305).

Por su parte, "los puntos de vista son categorías funcionales que no dependen primariamente de la forma o del contenido" (van Eemeren y Grootendorst, 2002: 44).

\section{2) MODELOS DIALÓGICOS Y ARGUMENTATIVOS}

Si se tuviera que describir qué es una argumentación se podría responder mediante algunas imágenes. Quizás algún lector se vería tentado a concebir la experiencia argumentativa como una discusión; sin embargo, otro la podría asociar con un diálogo de café, mientras que un tercero con una conferencia. En efecto, la argumentación tiene lugar en muchas formas de intercambio académico, familiar, político... y no debe identificarse inmediatamente con un conflicto, al menos en sentido "violento", ya que esta asociación podría perjudicar seriamente su desarrollo, cultivo y transmisión, en un escrupuloso afán por prevenir enfrentamientos.

Hay muchos modelos empleados para ejemplificar el intercambio de ideas, algunos de los cuales recurren a metáforas muy útiles. Para no pocos, un intercambio de ideas es un combate, prácticamente una guerra, en la que solo uno de los contendientes puede resultar victorioso: no triunfa la fuerza de las ideas, sino la fuerza verbal o en el peor de los casos, la fuerza física.

Otros pensadores recurren a la figura de un intercambio comercial, en el cual las partes negocian sus puntos de vista para llegar a un acuerdo.

Entre las principales imágenes para describir un debate destacan las cinco siguientes:

$\diamond$ Metáfora bélica:

debatir es luchar.

$\diamond$ Metáfora mercantil: debatir es comerciar. $\diamond$ Metáfora lúdico-deportiva: debatir es jugar. $\diamond$ Metáfora exploradora: debatir es viajar. $\diamond$ Metáfora constructora: debatir es construir (Cattani, 2003: 74).

Cada una de estas metáforas está asociada a un quehacer, una ejecución particular en la forma como argumentamos. Piénsese, a manera de ilustración, en la distinta actitud que despierta la metáfora bélica comparada con la mercantil, en donde desde el léxico y las estrategias, hasta la interacción asociada son radicalmente distintos. Algo semejante ocurre al comparar la metáfora constructora con la exploradora: la primera, parece tender a la consecución de un producto, un resultado, mientras que la segunda, puede estar más abierta a la imposibilidad de llegar a una conclusión específica; sin embargo, ambas desarrollan un espíritu cooperativo.

Ahora bien, nuestro quehacer argumentativo puede tener lugar en muchos contextos. Walton y Krabbe, en Arguments from Ignoran$c e$, plantean la existencia de diez distintas categorías dialógicas en las que la argumentación puede desarrollarse:

a) diálogo persuasivo: en el cual se pretende convencer a un interlocutor con 
el propósito de comprender las distintas posiciones;

b) debate: donde la finalidad es convencer a una tercera parte (generalmente, un auditorio) mediante la habilidad argumentativa y retórica;

c) indagación: empleada para adquirir conocimientos a través de la verificación o confutación de una conjetura;

d) trato: basado en la transacción y el consenso para obtener el mayor beneficio;

e) comisión: que tiende a la elaboración de un plan o decisión común, previa consideración de los pros y los contras;

f) diálogo pedagógico: característico de la función docente en la que se busca enseñar $y$ aprender para transmitir conocimientos;

g) deliberación: en la que se tiende a solucionar un problema práctico con la articulación de fines en común;

h) contienda: con la evidente intención de derrotar al oponente ante la manifestación de tesis encontradas;

i) entrevista: empleada para exponer la posición de un invitado, con el fin de difundir su punto de vista e informar al auditorio y por último;

j) consulta de expertos: requerida para la toma de decisiones operativas mediante información privilegiada (Cattani, 2003: 73).

Tal y como el lector podrá apreciar, son muchas y muy diversas las situaciones en las que cotidianamente se emplea la argumentación.

En el estudio de la argumentación, la lógica desempeña un papel muy importante, sin embargo, no es el único criterio que puede o debe considerarse. Nótese a este respecto que, stricto sensu, un análisis lógico de la experiencia argumentativa cotidiana llevaría a concluir que prácticamente todos los razonamientos son inválidos. En alguna medida, Aristóteles era consciente de este problema, ya que señaló que existe una forma de argumentación que no corresponde a los esquemas por él desarrollados, el entimema, cuyo estudio reserva para obras como Refutaciones Sofísticas y Tópicos.
El genio de Estagira comprendió que este tipo de razonamientos comportaba un examen distinto del de la simple y llana validez. La labor de discernir las premisas subyacentes, no explicitadas, implicaba una tarea por parte del interlocutor, empresa que, desafortunadamente, no alcanzó a normar.

En este sentido, la labor de van Eemeren y Grootendorst forma parte de una serie de esfuerzos de numerosos investigadores por llenar este vacío. Su enfoque tiene la virtud de que destaca que las falacias no solamente son violaciones de una norma de validez, sino de un conjunto de normas funcionales que tienen que ver con la comunicación.

La llamada "falacia de circularidad" o "petición de principio" puede servir para ilustrar eso, dado que, desde un punto de vista lógico, se trata de una tautología, pues la conclusión (la tesis que se defiende) figura como premisa. Sin embargo, argumentativamente no es una forma "correcta" de argumentar, es una falacia. Esto implica que el razonamiento, aunque es "válido" (siempre es verdadero), no necesariamente es "correcto". Esta aparente paradoja se aclara a través de la pragmática, la cual indica con toda claridad el origen de este error argumentativo. Nótese así que hay una diferencia entre "argumentación" y "validez".

De manera semejante, hay quienes argumentan con base en la repetición estratégica de su tesis, lo cual, lógicamente no es incorrecto (de hecho, se relaciona con reglas de inferencia como la "tautología" y la "reiteración"), aunque argumentativamente puede constituir un vicio.

Lo anterior sugiere que en la argumentación hay factores extra lógicos, es decir, factores o información adicional significativa que tienen que ver con la forma cómo los hablantes hacen uso de la lengua, a esto se le denomina pragmática.

En su sentido más amplio, la pragmática es el estudio de la comunicación lingüística en contexto. El lenguaje es el principal medio de comunicación entre las personas; sin embargo, el solo conocimiento de las palabras y la gramática de una lengua no garantiza el éxito en 
la comunicación. Las palabras pueden significar más (o algo distinto) de lo que dicen. En su interpretación intervienen una multiplicidad de factores, entre los cuales se encuentran la familiaridad con el contexto, las marcas de entonación y los supuestos culturales. La misma frase puede tener diferentes significados en diferentes ocasiones, $y$ se puede expresar la misma intención mediante diferentes medios lingüísticos. La pragmática se ocupa de fenómenos como estos (BlùmKulka, 1995: 67).

Es fácil corroborar lo anterior, al considerar una expresión como ¿quedó café? Formular esta pregunta un sábado, antes de ir de compras, es una forma de averiguar si es necesario comprarlo; en cambio, en una tarde de vacaciones durante la visita a la casa de un amigo puede equivaler a la petición de algo para beber. Discernir entre uno, otro u otros significados es propio de la competencia pragmática del lenguaje.

Junto a esta faceta, hay un: “... aspecto dialéctico [que] consiste en que hay dos partes que intentan resolver una diferencia de opinión mediante el intercambio metódico de pasos (moves) en una discusión" (van Eemeren, 2002: 29).

La conjunción de estos dos aspectos ha dado lugar a lo que se denomina "pragmadialéctica", la cual sirve de base al presente estudio. Para van Eemeren y Grootendorst, esta perspectiva involucra ambas características de la argumentación:

Debido a que los dialécticos consideran que cada argumento es parte de una discusión crítica, sea ésta explícita o implícita, su modelo proporciona reglas que especifican qué pasos (moves), en las diversas etapas de esta discusión, pueden contribuir a resolver una diferencia de opinión. Si este intercambio verbal metódico es concebido pragmáticamente, como una interacción de actos de habla, este enfoque, que es el que nosotros favorecemos, puede ser llamado pragma-dialéctico (2002: 26-27).
Este modelo de interpretación tiene como marco de referencia el desarrollo de una "discusión crítica", la cual se caracteriza porque su:

(...) propósito es lograr acuerdos acerca de la aceptabilidad o inaceptabilidad de los puntos de vista en discusión, averiguando si, mediante la argumentación, pueden o no ser adecuadamente defendidos de la duda o de la crítica (van Eemeren y Grootendorst, 2002: 55).

La argumentación, expresan estos autores, es un acto de habla complejo. Cuando hablamos, hacemos algo, hablar, pero nuestra habla tiene múltiples efectos: afirmamos algo, hacemos peticiones, ordenamos... Estos actos, que se pueden considerar como actos de habla elementales, pueden clasificarse en "asertivos", "directivos", "compromisorios", "expresivos" y "declarativos". Ellos desempeñan un papel, denominado "función comunicacional". En los asertivos, la función comunicacional es básicamente decir cómo es un objeto; en los directivos, lograr que el oyente haga algo; en los compromisorios, comprometerse a hacer algo; en los expresivos, expresar los sentimientos en relación con un evento o situación; $y$ en los declarativos, crear la situación que se expresa, en este último caso, por ejemplo, concluir una sesión mediante la frase "se levanta la sesión" (sobre el tema puede consultarse van Eemeren y Grootendorst, 2002: 58-60).

A diferencia de estos actos de habla elementales hay actos de habla complejos como la argumentación. En estos últimos, uno o diversos actos de habla elementales se insertan con un propósito que complementa la función del acto elemental, lo cual puede ilustrarse de la siguiente manera: en un proceso argumentativo, una descripción, además de describir, puede servir para fundamentar una determinada tesis. Tal es el caso de quien describe la tragedia del Hindenburg del 6 de mayo de 1937, para sustentar la afirmación "los dirigibles no son un medio seguro de transporte". Por un lado, la descripción transmite información, pero la función de su intervención tiene un sentido distinto: el acto descriptivo coexiste simultáneamente con el macroacto argumen- 
tativo. En efecto, “(...) la argumentación no tiene una función comunicacional en el nivel de la oración, sino en un nivel textual superior" (van Eemeren y Grootendorst, 2002: 50); este último nivel corresponde al de los actos de habla complejos.

De lo anterior, se colige claramente que:

(...) la constelación de actos de habla que constituye la argumentación no es autosuficiente, sino que debe estar conectada de una manera especial con otro acto de habla: el acto de habla en el cual se expresa el punto de vista que es apoyado por la argumentación (van Eemeren y Grootendorst, 2002: 50).

\section{3) LA PARADOJA DEL MIEDO}

La palabra "paradoja" proviene del griego parádoxos, que quiere decir "inesperado, increíble, extraño, maravilloso, raro, singular, extraordinario" (Diccionario Manual Griego-Español 1995: 450). Se trata de una voz compuesta por el prefijo pará-, "al lado de" y el sustantivo, ádoxos, voz relacionada con la de sobra conocida dóxa a través de la literatura filosófica, con un amplio campo semántico asociado a la "opinión, manera de ver, idea, parecer, creencia" (Diccionario Griego-Español, 1964: 157). Sin embargo, tal y como se aprecia, ádoxos antepone un prefijo negativo ( $a$-) a dóxa, de donde resulta su significado: "no glorioso, obscuro, que no goza de buena fama o reputación, inesperado, contrario a la opinión general; paradójico" (Diccionario Griego-Español, 1964: 23).

De lo anterior se colige que parádoxos se refiere a una situación en la que nos encontramos ante algo que causa extrañeza; $y$ así lo es en la presente sección de este artículo. La aquí denominada "paradoja del miedo" se refiere a que, en los procesos de argumentación, el miedo puede producirse tanto con intención como sin ella; incluso, es posible que pocas sean las situaciones argumentativas en las que no se suscite algún grado de temor. El motivo parece ser que en la mayor parte de las argumentaciones se ven involucrados diversos tipos de bienes cuya pérdida o menoscabo podrían generar temor, un temor que puede afectar la voluntad así como la inteligencia y por ende, la libertad del individuo en la toma de sus decisiones.

En conclusión, el miedo parece ser muy difícil de evitar en la argumentación humana.

\section{4) LAS REGLAS DE LA ARGUMENTACIÓN}

La argumentación posee reglas que han de respetarse. Adelino Cattani propone un conjunto de once reglas, de índole ética y pragmática, las cuales han de regular todo debate:

Primero, no te consideres infalible (...)

Segundo, busca un punto de partida común (...)

Tercero, atente a lo que crees cierto (...)

Cuarto, aporta las pruebas que se te piden (...)

Quinto, no eludas las objeciones (...)

Sexto, no eludas la carga de la prueba (...)

Séptimo, trata de ser pertinente (...)

Octavo, esfuérzate en ser claro (...)

Noveno, no deformes las posiciones ajenas (...)

Décimo, en condiciones de empate final, suspende el juicio, a no ser que comporte un daño mayor.

Undécimo, en presencia de elementos nuevos, acepta la reapertura del debate y la revisión del caso (2003: 128-129).

El carácter ético y pragmático se aprecia en la ausencia de normas que se refieran a la validez y corrección de los argumentos empleados. Es esta una ausencia muy importante de la propuesta de Cattani.

Por otro lado, van Eemeren y Grootendrost, con su enfoque pragmadialéctico, postulan que “(...) la razonabilidad no está determinada solamente por la norma de acuerdo intersubjetivo, sino que depende también de la norma "externa" de que este acuerdo debe ser alcanzado de una manera válida" (2002: 26).

Estos autores no proponen una ética en sentido moral, sino reglas comunicacionales. Quizá por esto no ofrecen una denominación específica para cada una de ellas, lo cual podría 
inducir a pensar que se trata de un decálogo (dado que se trata de diez enunciados). Dichas reglas son:

Regla 1: Las partes no deben impedirse unas a otras el presentar puntos de vista o el ponerlos en duda.

Regla 2: Una parte que presenta un punto de vista está obligada a defenderlo si la otra parte le solicita hacerlo.

Regla 3: El ataque de una parte en contra de un punto de vista debe referirse al punto de vista que realmente ha sido presentado por la otra parte.

Regla 4: Una parte solo puede defender su punto de vista presentando una argumentación que esté relacionada con ese punto de vista.

Regla 5: Una parte no puede presentar algo falsamente como si fuera una premisa dejada implícita por la otra parte, ni puede negar una premisa que él mismo ha dejado implícita.

Regla 6: Una parte no puede presentar falsamente una premisa como si fuera un punto de partida aceptado, ni puede negar una premisa que representa un punto de partida aceptado.

Regla 7: Una parte no puede considerar que un punto de vista ha sido defendido concluyentemente, si la defensa no se ha llevado a cabo por medio de un esquema argumentativo apropiado que se haya aplicado correctamente.

Regla 8: En su argumentación, las partes solo pueden usar argumentos que sean lógicamente válidos o que sean susceptibles de ser validados explicitando una o más premisas implícitas.

Regla 9: Una defensa fallida de un punto de vista debe tener como resultado el que la parte que lo presentó se retracte de él y una defensa concluyente debe tener como resultado el que la otra parte se retracte de sus dudas acerca del punto de vista.

Regla 10: Las partes no deben usar formulaciones que resulten insuficientemente claras o confusamente ambiguas $y$ deben interpretar las formulaciones de la parte contraria tan cuidadosa y exactamente como les sea posible (van Eemeren y Grootendrost, 2002: 223-224).

Con el respeto debido a tan eminentes investigadores, seguidamente se identifica cada una de estas reglas con una denominación particular, esto, para efectos mnemotécnicos y así facilitar su identificación y memorización:

Regla 1: Principio de libertad

Regla 2: Principio de carga de fundamentación

Regla 3: Principio de pertinencia activa

Regla 4: Principio de pertinencia defensiva

Regla 5: Principio de comprometimiento

Regla 6: Principio de lealtad

Regla 7: Principio de corrección argumentativa

Regla 8: Principio de lógica

Regla 9: Principio de humildad

Regla 10: Principio de claridad

Como se destacó supra, "una disputa no es necesariamente un conflicto, una pelea o una discusión en el sentido corriente" (ibid: 37). Por el contrario, una disputa es un encuentro dialógico en el que las ideas se explicitan $y$ fundamentan. Si bien, no siempre puede llegarse a "zanjar una disputa", la experiencia siempre permite enriquecer los puntos de vista encontrados. En este proceso:

Un argumentador solo puede resolver racionalmente una disputa referente a un punto de vista si, por medio de la argumentación, logra convencer a su interlocutor de la aceptabilidad de su punto de vista. La argumentación comprende toda la constelación de enunciados presentados en defensa de un punto de vista (ibid.: 34).

Esta es la solución óptima de una disputa. Empero, hay otras, ya que:

... zanjar una disputa significa que la diferencia de opinión simplemente se deja de lado. Esto puede hacerse de una manera más o menos civilizada, lanzando una moneda al aire, o más civilizadamente 
aún, solicitando el arbitraje de una tercera parte neutral: un árbitro, un ombudsman o un juez. También puede hacerse de una manera menos civilizada, saltando al cuello del adversario o, tal vez aún peor, recurriendo a la intimidación o al chantaje (van Eemeren y Grootendorst, 2002: 55).

Se ha pretendido criticar que la propuesta de van Eemeren y Grootendorst se aplicaría solo a "discusiones críticas", con la agravante de:

Pero no es fácil saber cuándo se está, de hecho, ante una discusión de esa naturaleza, con el propósito de ambas partes de que prevalezca la cláusula de confianza y credibilidad, necesarias para todo acuerdo o pacto (traducción del autor. Salvador, 2007: 303) ${ }^{1}$.

Los autores van Eemeren y Grootendorst reconocen expresamente que, entre las limitaciones de su modelo, figura el no poder aplicarse a todas las situaciones discursivas, pues se relaciona estrictamente con aquellos contextos en los que se trata de resolver una disputa de manera argumentativa (al respecto puede consultarse ibid.: 127). Sin embargo, las reglas por ellos expuestas se harán extensivas en este artículo a otros tipos de discurso.

\section{5) LA REGLAS DE LA ARGUMENTACIÓN Y EL MIEDO}

La argumentación y el miedo a menudo interactúan en el ámbito de las falacias.

$\mathrm{Al}$ asumir van Eemeren y Grootendorst una perspectiva comunicacional, enriquecen de sobremanera la teoría de las falacias, pues tradicionalmente estas consisten en errores meramente lógicos. En efecto, no se trata solamente de errores en los razonamientos, sino de:

1 Porém Não é fácil saber quando se está de fato diante de uma discussão dessa natureza, com empenho de ambas as partes, em que prevaleça a cláusula de confiança e de credibilidade, necessária a todo acordó ou pacto.
... obstáculos que impiden resolver una disputa a través del discurso argumentativo, el problema de las falacias se ve como una parte integral del problema que tienen los usuarios del lenguaje para lograr adecuadamente sus metas comunicacionales e interactivas, en un evento de habla específico, que ocurre en un contexto específico y una situación específica (2002: 231).

Se colige así que las falacias no solo apuntan a un tipo de vicio, la invalidez, sino que involucran aspectos mucho más amplios, tal y como las distintas reglas de la argumentación permiten apreciar.

Generalmente, la primera regla (el principio de libertad) se ve comprometida negativamente en contextos en los que se emplea el temor. En este sentido, menoscaban el derecho de toda persona a ser razonablemente convencida respecto de una tesis o en el peor de los casos, su derecho a sostener y fundamentar una tesis contraria.

\begin{abstract}
Atentar contra la libertad personal del oponente, negándole el derecho a presentar un punto de vista o a criticarlo, es un intento de eliminarlo como participante serio de la discusión. Esto se puede hacer presionándolo a abstenerse de presentar un punto de vista particular o de ponerlo en duda. También puede hacerse desacreditando su experiencia, imparcialidad, integridad o credibilidad. Generalmente tales maniobras no se ejecutan de una manera directa, sino por medio de desvíos sofisticados y retorcidos. Más que dirigirse directamente al oponente, a menudo están dirigidas a una audiencia que constituye un tercer partido (van Eemeren y Grootendorst, 2002: 128).
\end{abstract}

Tales violaciones comprenden al conocido argumentum ad baculum (falacia de apelación a la fuerza), así como, al argumentum ad hominem (falacia personal) que por lo general, no suelen expresarse de manera directa, sino indirecta. Tal es el caso de una expresión como "no quisiéramos pensar que usted (un 
compañero de trabajo) no apoya a su equipo". Sobre este tema van Eemeren y Grootendorst apuntan:

Una manera sofisticada, aunque no poco común, de utilizar amenazas para presionar al oponente es la manipulación de sus emociones. Por ejemplo, se le da a entender al oponente que, si comienza a poner en cuestión un punto de vista, será considerado responsable de herir o desilusionar a la persona que lo presentó. La amenaza contenida en este chantaje moral le hace sentir que ya no es libre de poner en duda el punto de vista (ibid.: 130).

Nótese que en el ejemplo se califica ipso facto el planteamiento de una tesis diferente como "un caso de falta de apoyo". Se obvian preguntas evidentes como: ¿debo apoyar a mis compañeros cuando están equivocados?, ¿es mi tesis un ejemplo de falta de apoyo per se? y la más importante, ¿es correcta la tesis contraria? No obstante, estas consideraciones son de carácter lógico, mientras que para el enfoque pragma-dialéctico es igual o mayormente importante que se menoscabe el principio de libertad. Esto no excluye que, al igual que ocurre en el campo de las falacias, se hayan infringido otros principios, ya que mediante este tipo de recursos no solo se afecta el principio de libertad, pues también se transgrede el "principio de comprometimiento", de acuerdo con el cual toda tesis (en este caso, la de los compañeros de trabajo) debe ser fundamentada.

Si bien algunos autores hablan del "mito de la argumentación no coercitiva" (al respecto véase Cattani, 2003: 57), lo cierto es que se trata de un tipo de interacción que como tal, ha de tener sus reglas. En todo caso, se procura mejorar sobre la base de una observación previa $y$ descripción de reglas (tal y como hacen van Eemeren $y$ Grootendorst), este quehacer.

Dado que el miedo consiste en una "pasión del ánimo que hace huir o rehusar aquello que se considera dañoso, arriesgado o peligroso. 2. Presunción o sospecha. 3. Recelo de un daño futuro" (Real Academia Española, 2001: 2150); resulta evidente que puede ser objeto de manipulación:
La manipulación de las emociones de la audiencia busca explotar sus prejuicios, los que no son directamente relevantes al punto de vista defendido, en vez de abocarse a defenderlo partiendo de premisas mutuamente acordadas por los participantes de la discusión. En este caso, el pathos toma el lugar del logos. Por esta razón, a veces tales violaciones de la Regla 4 son llamadas "falacias patéticas" (van Eemeren y Grootendorst, 2002: 153).

La Regla 4 o "principio de pertinencia defensiva", como puede apreciarse en la cita, posee un marcado compromiso lógico. En Retórica, Aristóteles había destacado la existencia de tres tipos de argumentos:

De entre las pruebas por persuasión, las que pueden obtenerse mediante el discurso son de tres especies: unas residen en el talante del que habla, otras en predisponer al oyente de alguna manera $y$, las últimas, en el discurso mismo, merced a lo que éste demuestra o parece demostrar (1999: 1356a, 175).

El talante del que habla se refiere a lo que en griego se conoce como éthos, es decir, el carácter o personalidad del orador. Involucra su fama, su reputación y sobre todo, la forma específica de cómo la moldea mediante su discurso.

Pues bien, <se persuade> por el talante (éthos), cuando el discurso es dicho de tal forma que hace al orador digno de crédito. Porque a las personas honradas las creemos más y con mayor rapidez, en general en todas las cosas, pero, desde luego, completamente en aquéllas en que no cabe la exactitud, sino que se prestan a duda; si bien es preciso que también esto acontezca por obra del discurso y no por tener prejuzgado cómo es el que habla. Por lo tanto, no <es cierto que>, en el arte, como afirman algunos tratadistas, la honradez del que habla no incorpore nada en orden a lo convincente, sino que, por así decirlo, casi es el talante personal quien constituye el 
más firme <medio de> persuasión (1999: 1356a5-15, 176, ni el paréntesis ni la itálica están en el original).

Por su parte, la predisposición de los oyentes se expresa en griego mediante la voz pathos, es decir, las emociones del auditorio (aunque también intervienen las emociones de la contraparte en la discusión).

De otro lado, <se persuade por la disposición> de los oyentes, cuando éstos son movidos a una pasión por medio del discurso. Pues no hacemos los mismos juicios estando tristes que estando alegres, o bien cuando amamos que cuando odiamos (1999: 1356a13-18, 177).

Finalmente, lógos es el término griego empleado para aludir a las propiedades argumentativas del discurso.

De otro lado, en fin, <los hombres $>$ se persuaden por el discurso, cuando les mostramos la verdad, o lo que parece serlo, a partir de lo que es convincente en cada caso (1999: 1356a17-19, 177).

Son muchas las emociones que pueden verse involucradas en una argumentación, empero, generalmente su empleo aparece asociado al argumentum ad populum (falacia de apelación al pueblo), el cual:

(...) es una falacia que puede observarse frecuentemente en manifestaciones públicas, reuniones políticas y asambleas religiosas. Su efecto depende de factores socio-psicológicos que juegan un rol en las reuniones de grandes grupos de personas. La persona que obtiene el mayor éxito en la manipulación de las emociones de los presentes es la que tiene mayores probabilidades de lograr su cometido. El verdadero demagogo sabe cómo manipular tanto las emociones positivas como las negativas y cómo llegar tanto al grupo en su conjunto como a los individuos que lo componen (van Eemeren y Grootendorst, 2002: 153).
Supra se indicó que esta forma de argumentar violenta el "principio de pertinencia defensiva", dado que en realidad, no tiene como objeto la tesis de la contraparte.

Otro tipo de argumento que involucra el temor, considera las consecuencias negativas de las tesis en conflicto.

Con respecto a los argumentos por consecuencia, una de las preguntas críticas que debe plantearse es si lo que se presenta como una consecuencia es realmente algo que podría ocurrir o no. Si un curso de acción se rechaza sobre la base de que tendría un resultado extremadamente negativo, en circunstancias de que en realidad ese efecto no se produciría en absoluto, entonces se está usando incorrectamente el esquema argumentativo. Un abuso común de este esquema argumentativo, en que se lleva al extremo una especulación sobre consecuencias negativas no fundamentales, es la falacia conocida como pendiente resbaladiza. Esta falacia consiste en sugerir erróneamente que, si se toma el curso de acción propuesto, se estaría yendo de mal en peor (van Eemeren y Grootendorst, 2002: 182-183).

Se aprecia que los errores en la argumentación se refieren aquí a aspectos como la posible falta de veracidad (al sostener una consecuencia que no tiene lugar) o yerros en la argumentación. Aquí, "los principios de lógica" $y$ de "corrección argumentativa" son los que no se estarían respetando.

También se relacionan con este tema, los argumentos que usan incorrectamente la relación "causa-efecto", las "generalizaciones" y la falacia denominada post hoc ergo propter hoc (por haber ocurrido después de esto, es, por lo tanto, por causa de esto).

Asimismo, van Eemeren y Grootendorst proponen la existencia de tres esquemas argumentativos básicos. Su modelo de análisis es bastante simple, puesto que ambos autores expresan que no pretenden asociarse con la línea de la tópica aristotélica; es más, se distinguen notablemente de 
ella. Sin embargo, el curso de la exposición sugiere que se trata de un esfuerzo en la misma línea del filósofo de Estagira.

De acuerdo con estos autores, "un esquema argumentativo es un indicador que señala cierta ruta dialéctica" elegida por un argumentador (van Eemeren y Grootendorst, 1992: 118). Los tres esquemas argumentativos básicos son:

a) la argumentación por sintomaticidad

b) la argumentación por similaridad

c) la argumentación por instrumentalidad

La primera de ellas se basa en una relación de concomitancia entre la aceptabilidad de las premisas y la conclusión; la segunda, en una relación analógica y la última, en una causal. En palabras de ellos:

En el primer tipo de argumentación, el hablante trata de convencer a su interlocutor mostrando que algo es sintomático de alguna otra cosa. Este tipo de argumentación está basado en un esquema argumentativo en que la aceptabilidad de las premisas se transfiere a la conclusión haciendo comprender que existe una relación de concomitancia entre lo que se afirma en el argumento y lo que se afirma en el punto de vista. La argumentación es presentada como si fuera una expresión, un fenómeno, un signo o algún otro tipo de síntoma de lo que se afirma en el punto de vista (1992: 116).

Más adelante, estos autores añaden:

Existen, por supuesto, muchas subcategorías de esquemas argumentativos. Entre los (sub)tipos de argumentación basados en una relación de concomitancia están, por ejemplo, aquellos que presentan algo como una cualidad inherente o como una parte característica de algo más general. Algunos (sub)tipos de argumentación basados en una relación de analogía son, por ejemplo, el hacer una comparación, el dar un ejemplo $y$ el hacer referencia a un modelo.
Entre los (sub)tipos de argumentación basados en una relación de causalidad, se incluyen aquellos que señalan las consecuencias de un curso de acción, los que presentan algo como un medio para lograr cierto fin y los que enfatizan la nobleza de una meta con el fin de justificar los medios propuestos para lograrla (1992: 117).

Cada uno de los esquemas argumentativos citados puede desarrollarse para inducir temor en la audiencia o la contraparte. A manera de ilustración, considérense casos como los siguientes:

a) Una madre le habla a su hijo sobre un amigo o amistad: "No me gusta que su nuevo amigo sea tan aficionado al rock pesado, ese tipo de música está asociada, por lo general, con el consumo de drogas".

Este es un claro ejemplo de "argumentación sintomática" en la que una característica se asume como definitoria de una categoría de personas (en el fondo, hay un complejo cúmulo de falacias presentes). Aquí, la asociación rock pesado-drogas se toma como un elemento disuasivo del cultivo y fortalecimiento de la nueva amistad, induciendo desconfianza, temor y recelo hacia el compañero del hijo.

b) La oposición de la Iglesia al derecho de las parejas a optar por la fertilización in vitro es una forma de fascismo moral.

Mediante una analogía establecida entre la Iglesia y el régimen fascista, se establece una asociación negativa en el auditorio para que desconfíe y no evalúe críticamente, la posición moral de la primera (¿se supone que no hay que escuchar a los fascistas?).

c) Si usted continúa con ese negocio, irá a la bancarrota.

Un mal económico que hay que temer, la quiebra, se establece como consecuencia causal directa de una operación mercantil. 


\section{6) UN PAR DE PRINCIPIOS SOBRE EL MANEJO DEL TEMOR}

Con base en la "paradoja del miedo", es necesario reconocer que el miedo puede suscitarse en el curso de una argumentación de manera involuntaria, aunque también intencional.

Por eso, es conveniente proponer un conjunto de principios en relación con su existencia. Tal y como se ha visto en la exposición de van Eemeren y Grootendorst, en general, el miedo incide fundamentalmente sobre cuatro reglas (aunque puede manifestarse en otras):

1) Principio de libertad: debe respetarse de manera imperativa la libertad del auditorio $y$ de las partes que intervienen en el conflicto.

De lo anterior, se colige que se ha de proscribir toda forma de intimidación directa o indirecta.

2) Principio de pertinencia defensiva: la argumentación debe concentrase en la tesis propuesta, sin incurrir en la manipulación patética.

3) Principio de corrección argumentativa: los esquemas argumentativos deben, primero que todo, ser ciertos. No han de proponerse relaciones, analogías o consecuencias negativas de una tesis, a menos que sean pertinentes. Debe prevenirse la manipulación de prejuicios. Las analogías deben ser equilibradas, no desproporcionadas, los efectos adversos deben ser apreciados en su correcta dimensión y sopesarse su pertinencia.

4) Principio de lógica: nuestros argumentos deben ser válidos y sobre todo, tener relación con la tesis que se defiende $y$ la que se ataca.

Tal y como puede apreciarse, estas breves cuatro reglas involucran aspectos pragmáticos, a la vez que lógicos. Se trata de una primera propuesta, que se mejorará conforme se profundice en la investigación en el tema, en procura de una mejoría en los procesos argumentativos que vivimos cada día.

\section{BIBLIOGRAFÍA}

Aristóteles. Retórica. Madrid: Editorial Gredos, 1999.

Bibliograf. Diccionario Manual GriegoEspañol. Barcelona: Bibliograf SA, 1995.

Blùm-Kulka, Shoshana. "Pragmática del discurso". El discurso como interacción social. Estudios sobre el discurso II. Una introducción multidisciplinaria. 2da. reimpresión. Teun A. van Dijk (ed.). Barcelona. Editorial Gedisa SA, 1995: 67-99.

Camacho Naranjo, Luis. Introducción a la lógica. lera. edición. San José, Costa Rica: Editorial Universidad de Costa Rica, 1983.

Cattani, Adelino. Los usos de la retórica. Madrid: Alianza Editorial SA, 2003.

Plantin, Christian. La argumentación. 2 da. reimpresión. Barcelona: Book Print Digital, 2008.

Real Academia Española. Diccionario de la Lengua Española h/z. 21va. edición. Madrid: Editorial Espasa Calpe SA, 2001.

Salvador Mosca, Lineide. "O espaço tensivo da controversia: uma abordagem discursivoargumentativa”. Filología e Lingüística Portuguesa. São Paulo: Universidad de São Paulo, 2007: 293-310.

Sopena. Diccionario Griego-Español. Barcelona: Editorial Sopena SA, 1964.

Van Eemeren, Frans H. y Grootendorst, Rob. Argumentación, comunicación y falacias. Una perspectiva pragma-dialéctica. 2da. edición. Santiago, Chile: Ediciones Universidad Católica de Chile, 2002.

Van Eemeren, Frans H.; Grootendorst, Rob; Jackson, Sally y Jacobs, Scott. "Argumentación". El discurso como estructura y proceso. Estudios sobre el discurso I. Una introducción multidisciplinaria. Teun van Dijk (ed.). 2da. reimpresión. Barcelona. Editorial Gedisa SA, 2003: 305-333.

Fecha de ingreso: 27/08/2012 Fecha de aprobación: 14/12/2012 
